\title{
Clinical Implications of Mismatch Repair Status in Patients With High-risk Stage II Colon Cancer
}

\author{
DONG WON BAEK ${ }^{1}$, BYUNG WOOG KANG ${ }^{1}$, SOO JUNG LEE ${ }^{1}$, HYE JIN KIM ${ }^{2}$, SU YEON PARK ${ }^{2}$, \\ JUN SEOK PARK ${ }^{2}$, GYU SEOG CHOI ${ }^{2}$, JIN HO BAEK ${ }^{1 *}$ and JONG GWANG KIM ${ }^{1 *}$ \\ ${ }^{1}$ Department of Oncology/Hematology, Kyungpook National University Chilgok Hospital, School of Medicine, \\ Kyungpook National University, Kyungpook National University \\ Cancer Research Institute, Daegu, Republic of Korea; \\ ${ }^{2}$ Department of Surgery, Kyungpook National University Chilgok Hospital, \\ School of Medicine, Kyungpook National University, Daegu, Republic of Korea
}

\begin{abstract}
Background/Aim: This study evaluated the clinical significance of the mismatch repair (MMR) status and prognostic factors in patients with high-risk stage II colon cancer (CC). Materials and Methods: This was a retrospective analysis of 237 patients diagnosed with highrisk stage II CC who had test results for MMR status. Results: Among the 237 patients, 76 (32.1\%) were identified as having a microsatellite instability-high (MSI$H$ ) status. No significant differences were identified in disease-free or overall survival according to the MMR status. Moreover, no association was found between the use of adjuvant chemotherapy and survival outcomes of the MSI-H group. In a multivariate survival analysis, the primary tumor location (right-sided versus left-sided, hazard $\operatorname{ratio}(H R)=0.172, p=0.003)$ and $T$-stage $(H R=4.764$, $p=0.005)$ were identified as independent prognostic factors for disease-free survival. Conclusion: The present study
\end{abstract}

This article is freely accessible online.

*These Authors contributed equally to this study.

Correspondence to: Jin Ho Baek, MD, Ph.D., Department of Oncology/Hematology, Kyungpook National University Chilgok Hospital, School of Medicine, Kyungpook National University, Kyungpook National University Cancer Research Institute, 807 Hogukno, Buk-gu, Daegu 41404, Republic of Korea. Tel: +82 532002623, Fax: +82 532002029, e-mail: wwhite71@hanmail.net and Jong Gwang Kim, MD, Ph.D., Department of Oncology/ Hematology, Kyungpook National University Chilgok Hospital, School of Medicine, Kyungpook National University, Kyungpook National University Cancer Research Institute, 807 Hogukno, Bukgu, Daegu 41404, Republic of Korea. Tel: +82 532002623, Fax: +82 532002029, e-mail: jkk21c@knu.ac.kr

Key Words: Mismatch repair, high-risk features, stage II colon cancer, adjuvant chemotherapy. found that the MMR status was neither prognostic nor predictive in patients with high-risk stage II CC.

Complete surgical resection is the primary treatment for patients with locoregional colon cancer (CC). The subsequent choice of adjuvant chemotherapy for patients with resected, non-metastatic $\mathrm{CC}$ then depends on the stage of the disease. For patients with stage III CC, the use of adjuvant chemotherapy such as FOLFOX (infusional fluorouracil, leucovorin plus oxaliplatin) or CAPOX (capecitabine plus oxaliplatin) has become the standard treatment $(1,2)$. However, for patients with stage II CC, the additional survival benefit from adjuvant chemotherapy varies according to certain clinicopathological parameters. Standard guidelines recommend that patients with low-risk stage II CC with high microsatellite instability (MSI-H) do not require any adjuvant chemotherapy, whereas adjuvant chemotherapy should be recommended for patients with high-risk stage II CC, which includes T4 tumors, a poorly differentiated histology, lymphovascular invasion, perineural invasion, bowel obstruction, localized perforation, positive margin, or inadequately sampled lymph nodes (<12 lymph nodes) (2-4).

MSI, the abnormal shortening or lengthening of DNA by 1-6 repeating base pair units, is the result of inactivation of the DNA mismatch repair (MMR) system and characterizes approximately $15 \%$ of CC (5). The MMR status is an important factor when deciding whether to use adjuvant chemotherapy for patients with stage II CC (6). According to previous studies, patients with MSI-H with CC showed a more favorable prognosis than those with microsatellitestable (MSS) tumors (7-9). Moreover, in the case of stage II CC, patients with low MSI (MSI-L) or MSS tumors showed improved outcomes with fluorouracil (FU)-based adjuvant chemotherapy, while patients with MSI-H tumors showed no statistically significant benefit from adjuvant chemotherapy (8). Although several previous studies already tried to prove 
an association between the MMR status and survival outcomes, the prognostic impact and predictive role of the MMR status in patients with high-risk stage II CC have not yet been clearly defined $(9,10)$.

Accordingly, the present study evaluated the clinical significance of the MMR status in patients with high-risk stage II CC. In addition, the prognostic effect of the MMR status was also investigated in relation to the tumor site, type of chemotherapy, and high-risk features.

\section{Materials and Methods}

Patients and treatment. This study retrospectively reviewed 1431 patients who were diagnosed with $\mathrm{CC}$ and underwent curative surgical resection at Kyungpook National University Chilgok Hospital (KNUCH) between January 2011 and December 2017. The patients were enrolled according to the following criteria: i) pathologically diagnosed with primary CC, ii) stage II CC classified by the seventh edition of the American Joint Committee on Cancer Staging Manual (11), iii) high-risk features, and iv) available test results for MMR status. A total of 237 patients met these criteria and were included in this study. The patient records were also reviewed for data on the medical history, age, sex, adjuvant chemotherapy regimen, surgical methods, and pathologic results. The study was approved by the Institutional Review Board of Kyungpook National University Hospital (KNUMCBIO_11).

All adjuvant chemotherapy was started 3 to 6 weeks after surgery. In the case of capecitabine monotherapy and CAPOX, the patients received chemotherapy every 3 weeks for 24 weeks ( 8 cycles) (12,13). In the case of FOLFOX and 5-fluorouracil/ leucovorin $(5-\mathrm{FU} / \mathrm{LV})$, the patients received chemotherapy every 2 weeks for 24 weeks $(12$ cycles) $(14,15)$. Dose modifications were performed according to predefined guidelines based on the toxicity (1). Observation without adjuvant chemotherapy was also an option for elderly patients or patients with an Eastern Cooperative Oncology Group (ECOG) performance status of 3 or more.

Definition of high-risk stage II CC. Patients with stage II CC who had at least one of the following poor prognostic features were classified as being at high-risk: T4 tumor, poorly differentiated histology, lymphovascular invasion, perineural invasion, bowel obstruction, localized perforation, positive margins, or inadequately sampled lymph nodes (<12 lymph nodes) (3).

Determination of MMR status. MSI was evaluated using an immunohistochemical (IHC) analysis of expression MMR proteins [MutL homolog 1 (MLH1), MutS homolog 2 (MSH2), MSH6, and postmeiotic segregation increased 2 (PMS2)] or molecular MSI testing based on a polymerase chain reaction assay (16). The IHC for MMR protein expression was performed on whole tumor sections using an automatic immunostainer (BenchMark XT; Ventana Medical Systems, Tucson, AZ, USA) according to the manufacturer's instructions. Primary monoclonal antibodies against $M L H 1$ (clone M1, prediluted; Ventana Medical Systems), MSH2 (clone G219, 1:100, Cellmark, Rocklin, CA, USA), MSH6 (clone 44, prediluted; Ventana Medical Systems), and PMS2 (clone mrq-28, 1:200; Cellmark) and an ultraView Universal DAB kit (Ventana Medical Systems) were applied to 4$\mu$ m-thick $10 \%$ formalin-fixed, paraffin-embedded tissue sections.
Tumors displaying loss of expression of one or more MMR proteins (loss of $P M S 2$, combined loss of $P M S 2$ and $M L H 1$, loss of MSH6, combined loss of MSH2 and MSH6) was considered to be MSI-H, whereas tumors with intact MMR proteins were classified as MSS.

For the molecular MSI testing, a panel consisting of five markers (D5S346, BAT26, BST25, D17S250, D2S123) was used. The amplified polymerase chain reaction products were analyzed using a Model 3500xL Genetic Analyzer (ThermoFisher Scientific, Seoul, Korea). A locus was called unstable if unequivocal instabilities were seen in the tumor sample in comparison with the paired normal DNA of the same patient. MSI was graded as high when two or more markers were unstable, low when one marker was unstable, and stable when all the markers were stable.

Statistical analysis. The descriptive statistics are reported as proportions and medians. The categorical variables were evaluated using a chi-square test and Fisher's exact test, as appropriate. Disease-free survival (DFS) was measured from the time of surgery to the time of tumor recurrence or death from any cause. Overall survival (OS) was calculated from the date of surgery to death from any cause. Data were censored if patients were free of recurrence or alive at the last follow-up. The Kapla-Meier method was used to estimate the DFS and OS. The survival curves were compared using a log-rank test according to the MMR status. Multivariate survival analyses were carried out using the Cox proportional hazard regression model. The hazard ratio (HR) and $95 \%$ confidence interval (CI) were estimated for each factor. A $p$-value of less than 0.05 was considered statistically significant. The statistical analyses were performed using SPSS for Windows (version 19.0; SPSS Inc., Chicago, IL, USA).

\section{Results}

Patient and tumor characteristics. The patient and tumor characteristics are summarized in Table I. The median age was 70 (range $=25-88$ ) years at the time of diagnosis, and 129 $(54.4 \%)$ patients were male. According to the test results for the MMR status, 76 (32.1\%) patients were classified as MSI-H. From a total of 237 eligible patients, $166(70.0 \%)$ received adjuvant chemotherapy, where 84 (50.6\%) received capecitabine alone, $69(41.6 \%)$ received FOLFOX, 8 (4.8\%) received CAPOX, and $5(3.0 \%)$ received $5-\mathrm{FU} / \mathrm{LV}$ as their adjuvant chemotherapy. The other $71(30 \%)$ patients did not receive any adjuvant chemotherapy due to old age or a poor general condition.

Prognostic value of MSI and factors affecting survival outcomes. With a median follow-up duration of 25.0 (6.480.0) months, the estimated 3-year DFS and OS rates were $90.5 \%$ and $92.1 \%$, respectively. During the analyses, 17 (7.2\%) patients experienced disease relapse and $19(8.0 \%)$ died. In the present study, no statistically significant differences were identified for DFS $(p=0.564)$ and OS $(p=0.627)$ according to the MMR status in high-risk stage II $\mathrm{CC}$. In the multivariate analysis, right-sided primary tumor location $(\mathrm{HR}=0.172,95 \% \mathrm{CI}=0.055-0.540, p=0.003)$ was 
Table I. Patient characteristics.

\begin{tabular}{|c|c|c|c|c|}
\hline \multirow[t]{2}{*}{ Factor } & \multirow{2}{*}{$\begin{array}{c}\text { Total } \\
(\mathrm{N}=237)\end{array}$} & \multicolumn{2}{|c|}{ MMR status } & \multirow[t]{2}{*}{$p$-Value } \\
\hline & & $\begin{array}{c}\text { MSI-H } \\
(\mathrm{N}=76,32.1 \%)\end{array}$ & $\begin{array}{c}\text { MSI-L/MSS } \\
(\mathrm{N}=161,67.9 \%)\end{array}$ & \\
\hline \multicolumn{5}{|l|}{ Age } \\
\hline Median (range) & $70(25-88)$ & $70(35-87)$ & $68(25-88)$ & 0.486 \\
\hline \multicolumn{5}{|l|}{ Gender, n $(\%)$} \\
\hline Male & $129(54.4 \%)$ & $41(53.9 \%)$ & $88(54.7 \%)$ & \multirow[t]{2}{*}{0.885} \\
\hline Female & $108(45.6 \%)$ & $35(46.1 \%)$ & $73(45.3 \%)$ & \\
\hline \multicolumn{5}{|c|}{ Primary tumor location, $\mathrm{n}(\%)$} \\
\hline Ascending colon & $88(37.1 \%)$ & $33(43.4 \%)$ & $55(34.2 \%)$ & \multirow[t]{3}{*}{0.039} \\
\hline Transverse colon & $44(18.6 \%)$ & $20(30.3 \%)$ & $24(14.9 \%)$ & \\
\hline Descending colon & $105(44.3 \%)$ & $23(26.3 \%)$ & $82(50.9 \%)$ & \\
\hline \multicolumn{5}{|l|}{ T-Stage, $\mathrm{n}(\%)$} \\
\hline T4 tumors & $40(16.9 \%)$ & $6(7.9 \%)$ & $34(21.1 \%)$ & \multirow[t]{2}{*}{0.015} \\
\hline T3 tumors & $197(83.1 \%)$ & $70(92.1 \%)$ & $127(78.9 \%)$ & \\
\hline \multicolumn{5}{|c|}{ No. of sampled LNs, n (\%) } \\
\hline$<12$ & $26(11.0 \%)$ & $2(2.6 \%)$ & $24(14.9 \%)$ & \multirow[t]{2}{*}{0.006} \\
\hline$\geq 12$ & $211(89.0 \%)$ & $74(97.4 \%)$ & $137(85.1 \%)$ & \\
\hline \multicolumn{5}{|c|}{ Positive margins, n (\%) } \\
\hline Yes & $1(0.4 \%)$ & 0 & $1(0.6 \%)$ & \multirow[t]{2}{*}{0.677} \\
\hline No & $236(99.6 \%)$ & $76(100 \%)$ & $160(99.4 \%)$ & \\
\hline \multicolumn{5}{|c|}{ High-grade tumor, n (\%) } \\
\hline Yes & $31(13.1 \%)$ & $21(27.6 \%)$ & $10(6.2 \%)$ & \multirow[t]{2}{*}{$<0.001$} \\
\hline No & $206(86.9 \%)$ & $55(72.4 \%)$ & $151(93.8 \%)$ & \\
\hline \multicolumn{5}{|c|}{ Perineural invasion, $\mathrm{n}(\%)$} \\
\hline Yes & $95(40.1 \%)$ & $14(18.4 \%)$ & $81(50.3 \%)$ & \multirow[t]{2}{*}{$<0.001$} \\
\hline No & $142(59.9 \%)$ & $62(81.6 \%)$ & $80(49.7 \%)$ & \\
\hline \multicolumn{5}{|c|}{ Lymphovascular invasion, n (\%) } \\
\hline Yes & $100(42.2 \%)$ & $21(27.6 \%)$ & $79(49.1 \%)$ & \multirow[t]{2}{*}{0.003} \\
\hline No & $137(57.8 \%)$ & $55(72.4 \%)$ & $82(50.9 \%)$ & \\
\hline \multicolumn{5}{|c|}{ Bowel obstruction, n (\%) } \\
\hline Yes & $8(3.4 \%)$ & $3(3.9 \%)$ & $5(3.1 \%)$ & \multirow[t]{2}{*}{0.857} \\
\hline No & $229(96.6 \%)$ & $73(96.1 \%)$ & $156(96.9 \%)$ & \\
\hline \multicolumn{5}{|c|}{ Localized perforation, $\mathrm{n}(\%)$} \\
\hline Yes & $9(3.8 \%)$ & $5(6.6 \%)$ & $4(2.5 \%)$ & \multirow[t]{2}{*}{0.491} \\
\hline No & $228(96.2 \%)$ & $71(93.4 \%)$ & $157(97.5 \%)$ & \\
\hline Chemotherapy, n (\% & & & & \\
\hline Yes & $166(70.0 \%)$ & $50(65.8 \%)$ & $116(72.0 \%)$ & 0.309 \\
\hline No & $71(30.0 \%)$ & $26(34.2 \%)$ & $45(28 \%)$ & \\
\hline Relapse, n (\%) & & & & \\
\hline Yes & $17(7.2 \%)$ & $5(6.6 \%)$ & $12(7.5 \%)$ & 0.208 \\
\hline No & $220(92.8 \%)$ & $71(93.4 \%)$ & $149(92.5 \%)$ & \\
\hline Death, n (\%) & & & & \\
\hline Yes & $19(8.0 \%)$ & $6(7.9 \%)$ & $13(8.1 \%)$ & 0.203 \\
\hline No & $218(92.0 \%)$ & $70(92.1 \%)$ & $148(91.9 \%)$ & \\
\hline
\end{tabular}

LNs: Lymph nodes, MMR: mismatch repair, MSI-H: microsatellite instability high, MSI-L/MSS: microsatellite instability low/microsatellite stable.

independently prognostic for better DFS, and T3 stage $(\mathrm{HR}=4.764,95 \% \mathrm{CI}=1.600-14.185, p=0.005)$ was identified as an independent prognostic factor for poorer DFS (Table II), while T3 stage $(\mathrm{HR}=3.588,95 \% \mathrm{CI}=1.177-10.943$, $p=0.025)$ and age $<65$ years $(\mathrm{HR}=1.089,95 \% \mathrm{CI}=1.021-$ $1.162, p=0.009)$ showed prognostic significance for poorer OS (Table III), regardless of the MMR status.
Predictive role of MSI for adjuvant chemotherapy. In the subgroup analysis, no significant differences were identified in the survival outcomes according to MMR status in the patients with high-risk stage II CC who received adjuvant chemotherapy (DFS, $p=0.535$; OS, $p=0.368$ ). In addition, the survival outcomes in the MSI-H group showed no statistically significant differences between the patients who received 
Table II. Univariate and multivariate analyses for disease-free survival.

\begin{tabular}{|c|c|c|c|c|c|}
\hline \multirow[t]{3}{*}{ Variable } & \multirow[t]{3}{*}{ Comparator $v s$. Reference } & \multicolumn{4}{|c|}{ Disease-free survival } \\
\hline & & \multicolumn{2}{|c|}{ Univariate analysis } & \multicolumn{2}{|c|}{ Multivariate analysis } \\
\hline & & HR $(95 \% \mathrm{CI})$ & $p$-Value & HR $(95 \% \mathrm{CI})$ & $p$-Value \\
\hline Age & $<65 v s . \geq 65$ Years & $1.782(0.581-5.474)$ & 0.311 & $1.054(0.997-1.114)$ & 0.064 \\
\hline Gender & Male $v s$. female & $0.871(0.330-2.280)$ & 0.773 & $1.229(0.450-3.352)$ & 0.687 \\
\hline Primary tumor location & Right $v s$. left side & $0.473(0.270-0.821)$ & 0.009 & $0.172(0.055-0.540)$ & 0.003 \\
\hline T-Stage & $\mathrm{T} 3$ vs. T4 & $4.181(1.604-10.871)$ & 0.003 & $4.764(1.600-14.185)$ & 0.005 \\
\hline MMR status & High $v s$. low/MSS & $0.741(0.258-2.090)$ & 0.564 & $1.589(0.494-5.112)$ & 0.437 \\
\hline
\end{tabular}

MMR: Mismatch repair, HR: hazard ratio, CI: confidence interval, MSS: microsatellite stable.

Table III. Univariate and multivariate analyses for overall survival.

\begin{tabular}{|c|c|c|c|c|c|}
\hline \multirow[t]{3}{*}{ Variable } & \multirow[t]{3}{*}{ Comparator $v s$. Reference } & \multicolumn{4}{|c|}{ Overall survival } \\
\hline & & \multicolumn{2}{|c|}{ Univariate analysis } & \multicolumn{2}{|c|}{ Multivariate analysis } \\
\hline & & HR $(95 \%$ CI $)$ & $p$-Value & HR $(95 \% \mathrm{CI})$ & $p$-Value \\
\hline Age & $<65 v s . \geq 65$ Years & $1.082(1.020-1.141)$ & 0.008 & $1.089(1.021-1.162)$ & 0.009 \\
\hline Gender & Male vs. female & $0.369(0.121-1.114)$ & 0.077 & $3.011(0.966-9.384)$ & 0.057 \\
\hline Primary tumor location & Right $v s$. left side & $1.712(0.767-5.109)$ & 0.158 & $0.391(0.145-1.052)$ & 0.063 \\
\hline T-Stage & $\mathrm{T} 3 v s . \mathrm{T} 4$ & $3.140(1.233-7.978)$ & 0.016 & $3.588(1.177-10.943)$ & 0.025 \\
\hline MMR status & High $v s$. low/MSS & $0.781(0.477-3.411)$ & 0.627 & $1.527(0.488-4.781)$ & 0.467 \\
\hline
\end{tabular}

MMR: Mismatch repair, HR: hazard ratio, CI: confidence interval, MSS: microsatellite stable.

adjuvant chemotherapy and who did not (DFS, $p=0.124$; OS, $p=0.225$ ). Meanwhile, the patients who received FOLFOX or CAPOX as an adjuvant chemotherapy showed a superior OS when compared to the patients who received 5-FU/LV or capecitabine alone, regardless of the MMR status $(p=0.048$, Figure 1). However, for the MSI-H group, there were no statistically significant differences in DFS $(p=0.427)$ or OS $(p=0.155)$ according to the type of chemotherapy.

MMR status and primary tumor location. The primary tumors were located at the ascending colon in $88(37.1 \%)$ patients, transverse colon in $44(18.6 \%)$ patients, and descending colon in $105(44.3 \%)$ patients (Table I). To evaluate the prognostic value of right-sided $\mathrm{CC}$ versus left-sided $\mathrm{CC}$, the patients were classified as having right-sided cancer if the primary tumor was located in the cecum, ascending colon, hepatic flexure, or transverse colon, and left-sided cancer if the tumor site was within the splenic flexure, descending colon, sigmoid colon, or recto-sigmoid junction. As a result, $132(55.7 \%)$ patients were classified with right-sided CC and 105 (44.3\%) with left-sided $\mathrm{CC}$. The MSI-H frequency was higher for right-sided CC $(n=53,40.2 \%)$ than left-sided CC $(n=23,21.9 \%)$. DFS was statistically significantly better for patients with right-sided CC than those with left-sided $\mathrm{CC}$, regardless of the MMR status $(p=0.004$, Figure 2A). In the MSI-H group, DFS was also significantly better for the patients with right-sided $\mathrm{CC}$ ( $p=0.018$, Figure 2B). For the patients with right-sided or leftsided $\mathrm{CC}$, the MMR status was not associated with any statistical differences in DFS and OS.

MMR status and high-risk features. In the multivariate analysis, the T-stage, primary tumor location, and age were all identified as independent prognostic factors, regardless of the MMR status. However, when the individual high-risk features were analyzed according to the MMR status, a poorly differentiated histology conferred inferior DFS ( $p=0.001$, Figure 3A) and OS ( $p=0.014$, Figure 3B) for patients with MSI-H CC, while T4 tumors were significantly associated with poor DFS ( $p=0.011$, Figure 4A) and OS $(p=0.034$, Figure 4B) for those with MSI-L/MSS CC.

\section{Discussion}

The present study investigated the clinical significance of the MMR status and factors affecting prognosis in a relatively large cohort of patients with high-risk stage II CC. To the best 
of our knowledge, this is the first study to evaluate the prognostic value and predictive role of the MMR status in patients with high-risk stage II CC. However, the present results suggest that the MMR status has no definite prognostic value, and the effect of adjuvant chemotherapy did not lead to any survival difference between MSI-H and MSIL/MSS. However, the primary tumor location and T-stage were identified as prognostic factors in high-risk stage II CC.

Data from the Pan-European Trials in Adjuvant Colon Cancer 3 (PETACC-3 trial) (17) and another large study (18) showed that tumor specimens characterized as MSI-H were more common in stage II CC (22\%) than in stage III CC $(12 \%)$ or stage IV CC $(3.5 \%)$. While there are no definite data on the frequency of MSI-H, especially in high-risk stage II CC, the rate of MSI-H was $32.1 \%$ in the present study, which is higher than previous data. However, a recent study of the molecular classification of $\mathrm{CC}$ based on a messenger RNA expression profile analysis showed deficient MMR (dMMR) in $30.1 \%$ of patients, most of whom had stage II or stage III CC (19). Furthermore, in a large cohort study of IHC testing for the MMR status in stage II CC, the dMMR rate was $34.1 \%$ (20). Several studies already associated a higher dMMR rate with old age and right-sided tumor, where up to $45 \%$ of tumors were dMMR in patients over 80 years, and right-sided tumors had a higher dMMR rate than leftsided tumors (20-22). Thus, the data of the current study are consistent with these of previous reports. In the present study, $60 \%$ of the patients were older than 70 years and $55.7 \%$ had right-sided tumors.

When assessing the prognostic value of the MMR status with regard to OS and DFS, the MMR status showed no effect on the survival outcomes of the patients with high-risk stage II CC. MSI-H is generally associated with a better prognosis than MMS tumor $(23,24)$. A retrospective analysis of the MMR status in 1,913 patients with stage II CC showed that the recurrence rate for those with dMMR tumors was significantly lower than that for those with MMRproficient tumors (25). Notwithstanding this, Vogelaar et al. reported a worse survival trend for patients with MSI-H stage II CC (26). However, since the present study only included patients with stage II CC with high-risk features, the current results suggest that high-risk features have a more predominant effect on patient survival than the MMR status.

The present study indicated that the MMR status has no definite predictive role in high-risk stage II CC. Based on in vitro data showing that $\mathrm{CC}$ cell lines displaying MSI-H were less responsive to 5-FU than MSS cell lines (27-29), several clinical studies have suggested that patients with stage II MSI-H tumors do not benefit from 5-FU-based adjuvant chemotherapy $(9,30)$. Furthermore, Christine et al. demonstrated that an MSI-H tumor status can lead to a detrimental impact from adjuvant chemotherapy with fluoropyrimidine in patients with stage II CC (8). In contrast,

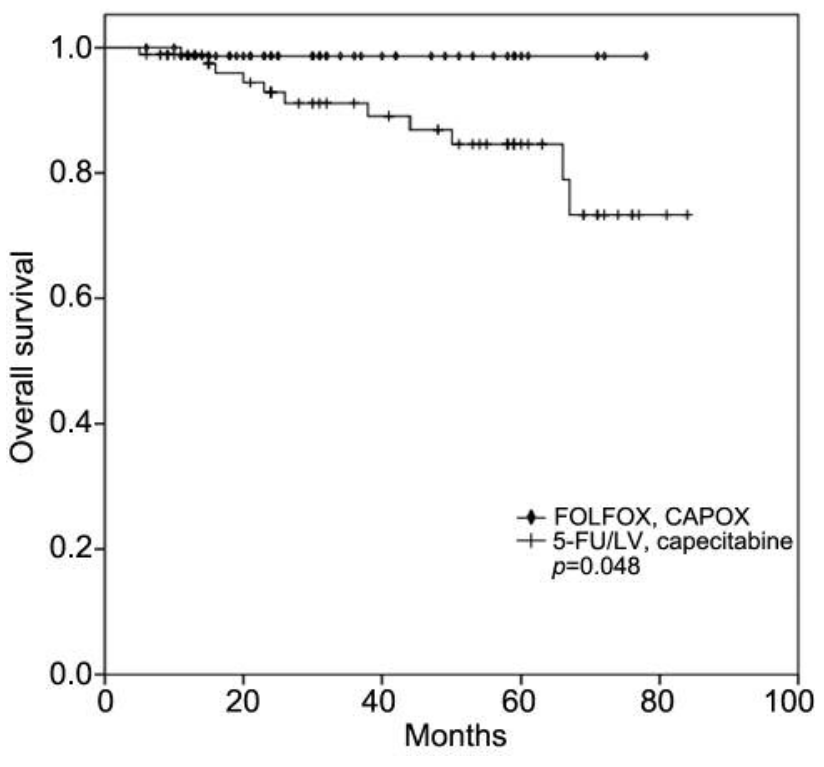

Figure 1. Kaplan-Meier survival curves for overall survival stratified as FOLFOX (infusional fluorouracil, leucovorin plus oxaliplatin) or CAPOX (capecitabine plus oxaliplatin) versus 5-FU/LV (5fluorouracil/leucovorin) or capecitabine regardless of the mismatch repair status in the patients with high-risk stage II colon cancer who received adjuvant chemotherapy.

Hutchins et al. reported that dMMR has neither a predictive role nor detrimental impact on chemotherapy (25). Contrary to previous reports, an article by Sinicrope et al. concerning 2,141 patients with colorectal cancer reported treatment benefits from 5-FU for those with stage III MSI-H disease $(8,9)$. Nevertheless, there is still insufficient research focused on high-risk stage II CC, and unfortunately, the data from the current study does not provide convincing evidence of differences between MSI-H and MSI-L/MSS as a result of adjuvant chemotherapy. However, this study did show no statistically proven detrimental effect.

Adjuvant chemotherapy using 5-FU and LV is the standard of care for patients with low-risk stage II CC $(1,2)$. Adding oxaliplatin to 5-FU-based therapy additionally improves DFS and OS in patients with stage III CC $(14,31,32)$. However, some previous studies have shown no benefit of the addition of oxaliplatin to adjuvant regimens for patients with high-risk stage II CC $(33,34)$. Furthermore, in the updated Multicenter International Study of Oxaliplatin/Fluorouracil/Leucovorin in the Adjuvant Treatment of Colon Cancer (MOSAIC) study with 10-year follow-up, no benefit from oxaliplatin was observed for either DFS or OS in patients with stage II CC. However, in patients with high-risk stage II CC, the estimated 10-year probability of OS was $75.4 \%$ for those treated with FOLFOX and $71.7 \%$ for those treated with 5-FU/LV $(p=0.058)$ (2). The current study found that adding oxaliplatin to $5-\mathrm{FU}$ as 

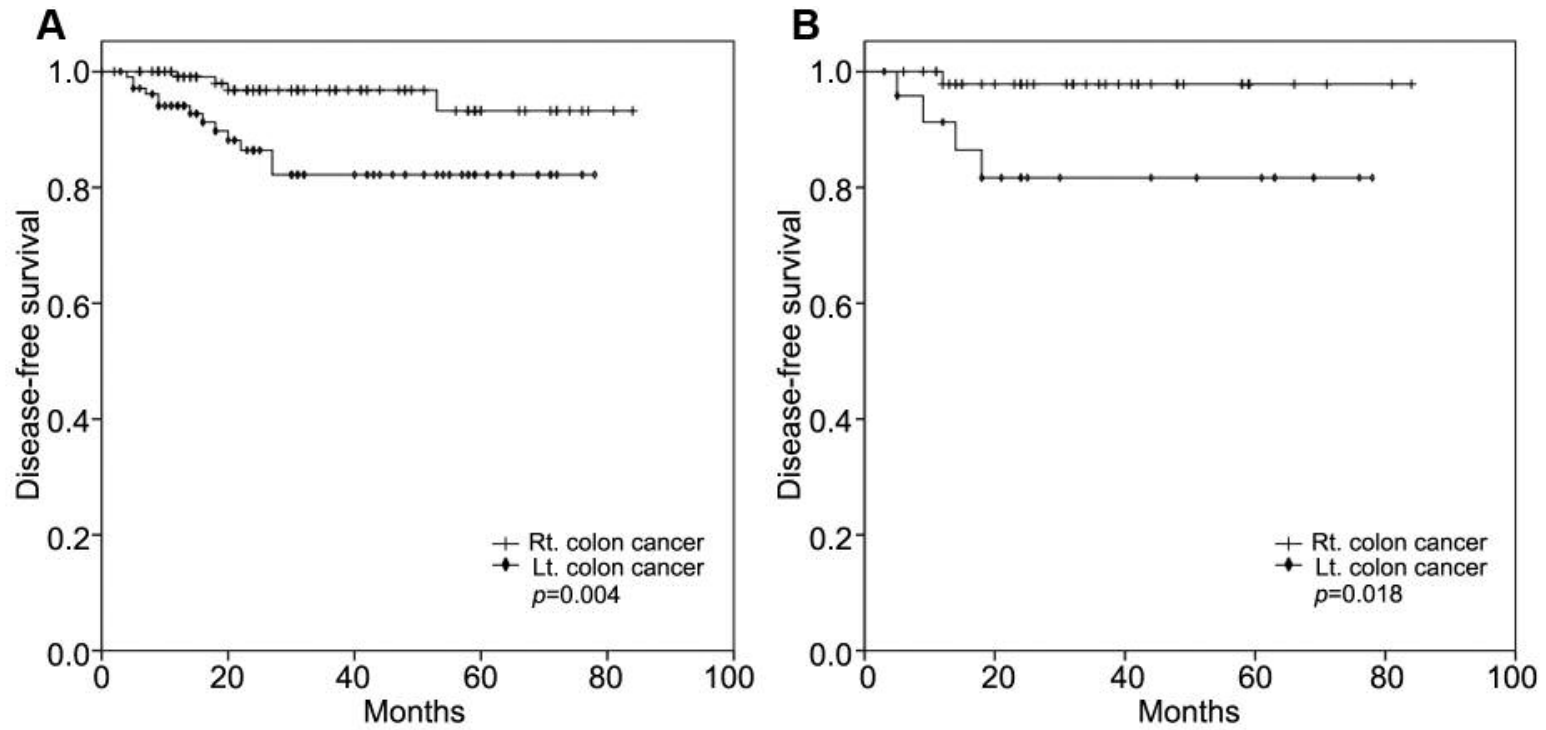

Figure 2. Kaplan-Meier survival curves for disease-free survival stratified as right-sided colon cancer versus left-sided colon cancer regardless of the mismatch repair status $(A)$ and as right-sided versus left-sided colon cancer in the group with microsatellite instability-high colon cancer (B).
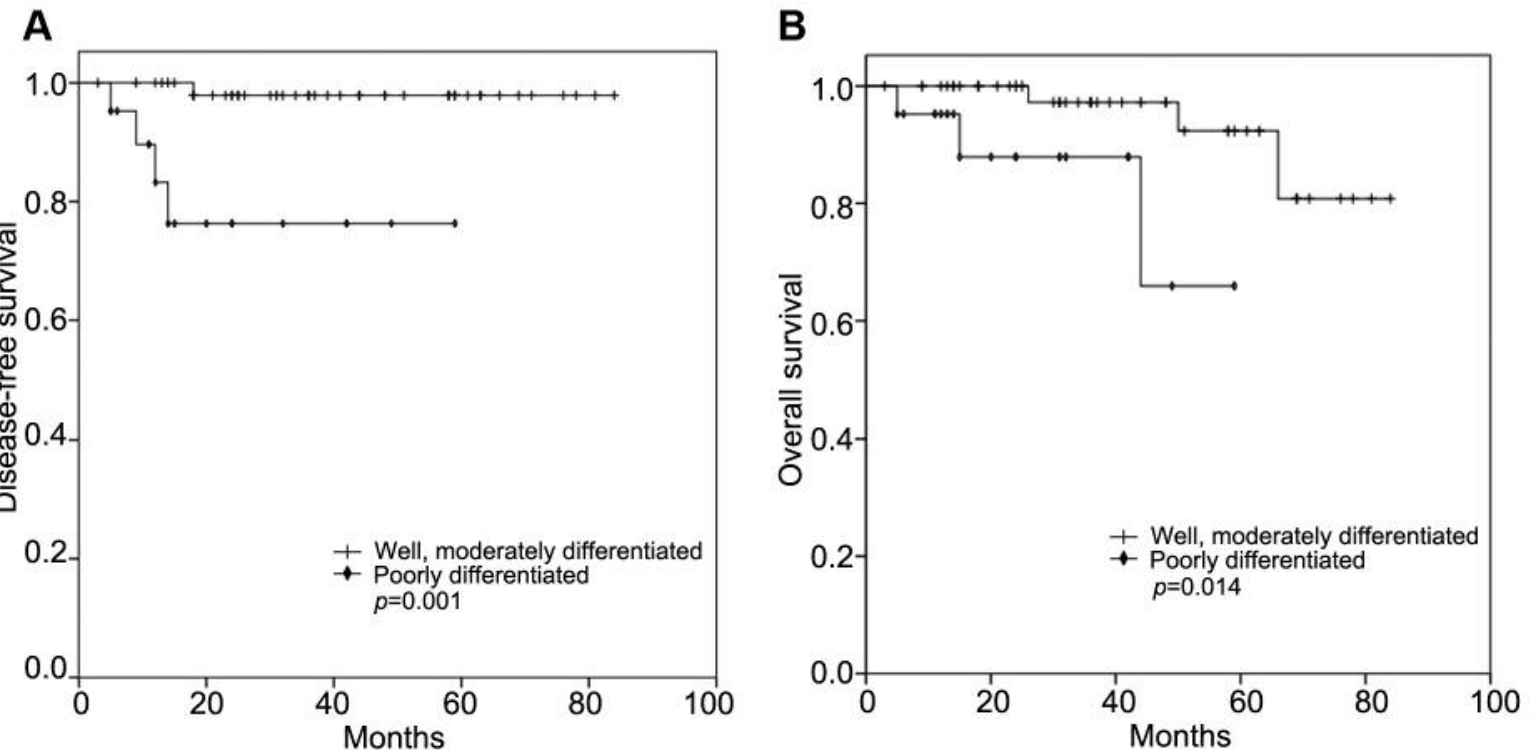

Figure 3. Kaplan-Meier survival curves for disease-free (A) and overall (B) survival of patients with microsatellite instability-high colon cancer according to histological differentiation.

an adjuvant chemotherapy improved OS $(p=0.048)$, regardless of the MMR status. However, further investigation is needed to confirm the definitive impact of oxaliplatin on survival in patients with MSI-H high-risk stage II CC.

The present study also confirms earlier reports that T4 tumors are significantly associated with a poor prognosis, regardless of the MMR status $(35,36)$. Moreover, poorly differentiated histology led to inferior survival outcomes, especially in MSI-H CC. However, the potential impact of the primary tumor site remains unclear, although the present data suggested improved survival outcomes for right-sided CC over left-sided CC in high-risk stage II CC. Moreover, a retrospective study based on Surveillance, Epidemiology, and End Results data reported that right-sided CC led to better survival than left-sided CC in the case of stage I-II CC, while the converse was true in the case of stage III-IV CC (37). 
A

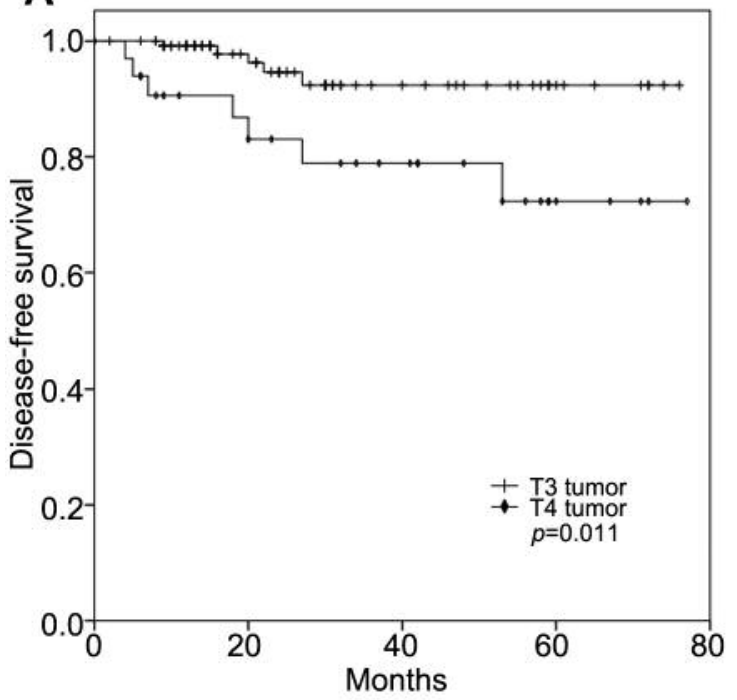

B

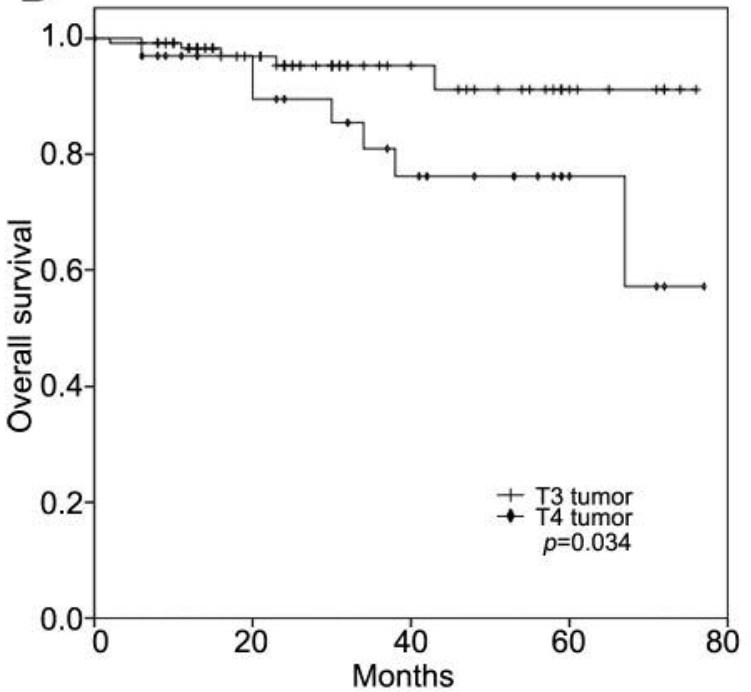

Figure 4. Kaplan-Meier survival curves for disease-free (A) and overall (B) survival of patients with microsatellite instability-low/microsatellite stable colon cancer according to T-stage.

In conclusion, the MMR status was found to be neither prognostic nor predictive in patients with high-risk stage II $\mathrm{CC}$. Therefore, as for patients with stage III CC, adjuvant chemotherapy following curative resection should also be recommended for those with high-risk stage II CC with MSI$\mathrm{H}$. Adding oxaliplatin to 5-FU-based chemotherapy is also worth considering for patients with high-risk stage II CC. However, well-designed prospective, randomized, controlled studies are warranted to confirm these results.

\section{Conflicts of Interest}

The Authors declare that they have no conflict of interest in regard to this study.

\section{Authors' Contributions}

All Authors contributed to the design and implementation of the research, to the analysis of the results and to the writing of the article.

\section{Ethical Approval}

All procedures performed in studies involving human participants were in accordance with the ethical standards of the institutional and/or national research committee and with the 1964 Declaration of Helsinki and its later amendments or comparable ethical standards.

\section{Acknowledgements}

This research was supported by a Kyungpook National University Research Fund, 2018.

\section{References}

1 André T, Boni C, Mounedji-Boudiaf L, Navarro M, Tabernero J, Hickish T, Topham C, Zaninelli M, Clingan P, Bridgewater J, TabahFisch I and de Gramont A: Oxaliplatin, fluorouracil, and leucovorin as adjuvant treatment for colon cancer. $\mathrm{N}$ Engl J Med 350: 23432351, 2004. PMID: 15175436, DOI: 10.1056/ NEJMoa032709

2 André T, de Gramont A, Vernerey D, Chibaudel B, Bonnetain F, Tijeras-Raballand A, Scriva A, Hickish T, Tabernero J, Van Laethem JL, Banzi M, Maartense E, Shmueli E, Carlsson GU, Scheithauer W, Papamichael D, Möehler M, Landolfi S, Demetter P, Colote S, Tournigand C, Louvet C, Duval A, Fléjou JF and de Gramont A: Adjuvant fluorouracil, leucovorin, and oxaliplatin in stage II to III colon cancer: Updated 10-year survival and outcomes according to BRAF mutation and mismatch repair status of the MOSAIC Study. J Clin Oncol 33: 4176-4187, 2015. PMID: 26527776, DOI: 10.1200/ JCO.2015.63.4238

3 Compton CC, Fielding LP, Burgart LJ, Conley B, Cooper HS, Hamilton SR, Hammond ME, Henson DE, Hutter RV, Nagle RB, Nielsen ML, Sargent DJ, Taylor CR, Welton M and Willett C: Prognostic factors in colorectal cancer. College of American Pathologists Consensus Statement 1999. Arch Pathol Lab Med 124: 979-994, 2000. PMID: 10888773, DOI: 10.1043/00039985(2000)124<0979:PFICC>2.0.CO;2

4 Benson AB, Schrag D, Somerfield MR, Cohen AM, Figueredo AT, Flynn PJ, Krzyzanowska MK, Maroun J, McAllister P, Van Cutsem E, Brouwers M, Charette M and Haller DG: American Society of Clinical Oncology recommendations on adjuvant chemotherapy for stage II colon cancer. J Clin Oncol 22: 34083419, 2004. PMID: 15199089, DOI: 10.1200/JCO.2004.05.063

5 Thibodeau SN, Bren G and Schaid D: Microsatellite instability in cancer of the proximal colon. Science 260: 816-819, 1993. PMID: 8484122, DOI: 10.1126/science. 8484112 
6 Markowitz SD and Bertagnolli MM: Molecular origins of cancer: Molecular basis of colorectal cancer. N Engl J Med 361: 2449-2460, 1993. PMID: 20018966, DOI: 10.1056/ NEJMra0804588

7 Klingbiel D, Saridaki Z, Roth AD, Bosman FT, Delorenzi M and Tejpar S: Prognosis of stage II and III colon cancer treated with adjuvant 5-fluorouracil or FOLFIRI in relation to microsatellite status: Results of the PETACC-3 trial. Ann Oncol 26: 126-132, 2015. PMID: 25361982, DOI: 10.1093/annonc/mdu499

8 Ribic CM, Sargent DJ, Moore MJ, Thibodeau SN, French AJ, Goldberg RM, Hamilton SR, Laurent-Puig P, Gryfe R, Shepherd LE, Tu D, Redston M and Gallinger S: Tumor microsatelliteinstability status as a predictor of benefit from fluorouracil-based adjuvant chemotherapy for colon cancer. N Engl J Med 349: 247257, 2003. PMID: 12867608, DOI: 10.1056/ NEJMoa022289

9 Sargent DJ, Marsoni S, Monges G, Thibodeau SN, Labianca R, Hamilton SR, French AJ, Kabat B, Foster NR, Torri V, Ribic C, Grothey A, Moore M, Zaniboni A, Seitz JF, Sinicrope F and Gallinger S: Defective mismatch repair as a predictive marker for lack of efficacy of fluorouracil-based adjuvant therapy in colon cancer. J Clin Oncol 28: 3219-3226, 2010. PMID: 20498393, DOI: $10.1200 / J C O .2009 .27 .1825$

10 Tejpar S, Bosman F, Delorenzi M , Fiocca R, Yan P, Klingbiel D, Dietrich D, Van Cutsem E, Labianca R and Roth A: Microsatellite instability (MSI) in stage II and III colon cancer treated with 5FU-LV or 5FU-LV and irinotecan (PETACC 3EORTC 40993-SAKK 60/00 trial). J Clin Oncol 27: 4001, 2009. PMID: 27961826, DOI: 10.11200/jco.2009.27.15_suppl.4001

11 Edge SB and Compton CC: The American Joint Committee on Cancer: the 7th edition of the AJCC Cancer Staging Manual and the future of TNM. Ann Surg Oncol 17: 1471-1474, 2010. PMID: 20180029, DOI: 10.1245/s10434-010-0985-4

12 Twelves C, Wong A, Nowacki MP, Abt M, Burris H, Carrato A, Cassidy J, Cervantes A, Fagerberg J, Georgoulias V, Husseini F, Jodrell D, Koralewski P, Kröning H, Maroun J, Marschner N, McKendrick J, Pawlicki M, Rosso R, Schüller J, Seitz JF, Stabuc B, Tujakowski J, Van Hazel G, Zaluski J and Scheithauer W: Capecitabine as adjuvant treatment for stage III colon cancer. N Engl J Med 352: 2696-2704, 2005. PMID: 15987918, DOI: 10.1056/NEJMoa043116

13 Haller DG, Tabernero J, Maroun J, de Braud F, Price T, Van Cutsem E, Hill M, Gilberg F, Rittweger K and Schmoll HJ: Capecitabine plus oxaliplatin compared with fluorouracil and folinic acid as adjuvant therapy for stage III colon cancer. J Clin Oncol 29: 1465-1471, 2011. PMID: 21383294, DOI: 10.1200/JCO.2010.33.6297

14 André T, Sargent D, Tabernero J, O’Connell M, Buyse M, Sobrero A, Misset JL, Boni C and de Gramont A: Current issues in adjuvant treatment of stage II colon cancer. Ann Surg Oncol 13: 887-898, 2006. PMID: 16614880, DOI: 10.1245/ ASO.2006.07.003

15 Haller DG, Catalano PJ, Macdonald JS, O'Rourke MA, Frontiera MS, Jackson DV and Mayer RJ: Phase III study of fluorouracil, leucovorin, and levamisole in high-risk stage II and III colon cancer: Final report of Intergroup 0089. J Clin Oncol 23: 8671-8678, 2005. PMID: 16314627, DOI: 10.1200/ JCO.2004.00.5686

16 Lindor NM, Burgart LJ, Leontovich O, Goldberg RM, Cunningham JM, Sargent DJ, Walsh-Vockley C, Petersen GM, Walsh MD, Leggett BA, Young JP, Barker MA, Jass JR, Hopper
J, Gallinger S, Bapat B, Redston $\mathrm{M}$ and Thibodeau SN: Immunohistochemistry versus microsatellite instability testing in phenotyping colorectal tumors. J Clin Oncol 20: 1043-1048, 2002. PMID: 11844828, DOI: 10.1200/JCO.2002.20.4.1043

17 Roth AD, Tejpar S, Delorenzi M, Yan P, Fiocca R, Klingbiel D, Dietrich D, Biesmans B, Bodoky G, Barone C, Aranda E, Nordlinger B, Cisar L, Labianca R, Cunningham D, Van Cutsem $\mathrm{E}$ and Bosman F: Prognostic role of KRAS and BRAF in stage II and III resected colon cancer: Results of the translational study on the PETACC-3, EORTC 40993, SAKK 60-00 trial. J Clin Oncol 28: 466-474, 2010. PMID: 20008640, DOI: 10.1200/JCO.2009.23.3452

18 Koopman M, Kortman GA, Mekenkamp L, Ligtenberg MJ, Hoogerbrugge N, Antonini NF, Punt CJ and van Krieken JH: Deficient mismatch repair system in patients with sporadic advanced colorectal cancer. Br J Cancer 100: 266-273, 2009. PMID: 19165197, DOI: 10.1038/sj.bjc.6604867

19 Marisa L, de Reyniès A, Duval A, Selves J, Gaub MP, Vescovo L, Etienne-Grimaldi MC, Schiappa R, Guenot D, Ayadi M, Kirzin S, Chazal M, Fléjou JF, Benchimol D, Berger A, Lagarde A, Pencreach E, Piard F, Elias D, Parc Y, Olschwang S, Milano G, Laurent-Puig P and Boige V: Gene expression classification of colon cancer into molecular subtypes: characterization, validation, and prognostic value. PLoS Med 10: e1001453, 2013. PMID: 23700391, DOI: 10.1371/ journal.pmed.1001453

20 Grant M, Haydon A, Au L, Wilkins S, Oliva K, Segelov E, Antill Y, Carne P, Ranchod P, Polglase A, Farmer C, Chin M, Wale R, Simpson P, Bell S, Skinner S, McMurrick P and Shapiro J: Immunohistochemistry testing for mismatch repair deficiency in stage 2 colon cancer: A cohort study of two cancer centres. Int J Surg 51: 71-75, 2018. PMID: 29367039, DOI: 10.1016/ j.ijsu.2018.01.020

21 O'Connor ES, Greenblatt DY, LoConte NK, Gangnon RE, Liou JI, Heise CP and Smith MA: Adjuvant chemotherapy for stage II colon cancer with poor prognostic features. J Clin Oncol 29: 3381-3388, 2011. PMID: 21788561, DOI: 10.1200/ JCO.2010.34.3426

22 Guinney J, Dienstmann R, Wang X, de Reyniès A, Schlicker A, Soneson C, Marisa L, Roepman P, Nyamundanda G, Angelino P, Bot BM, Morris JS, Simon IM, Gerster S, Fessler E, De Sousa E Melo F, Missiaglia E, Ramay H, Barras D, Homicsko K, Maru D, Manyam GC, Broom B, Boige V, PerezVillamil B, Laderas T, Salazar R, Gray JW, Hanahan D, Tabernero J, Bernards R, Friend SH, Laurent-Puig P, Medema JP, Sadanandam A, Wessels L, Delorenzi M, Kopetz S, Vermeulen L and Tejpar S: The consensus molecular subtypes of colorectal cancer. Nat Med 21: 1350-1356, 2015. PMID: 26457759, DOI: 10.1036/nm.3967

23 Kim GP, Colangelo LH, Wieand HS, Paik S, Kirsch IR, Wolmark N and Allegra CJ: Prognostic and predictive roles of high-degree microsatellite instability in colon cancer: A National Cancer Institute-National Surgical Adjuvant Breast and Bowel Project Collaborative Study. J Clin Oncol 25: 767-772, 2007. PMID: 17228023, DOI: 10.1200/JCO.2006.05.8172

24 Xiao H, Yoon YS, Hong SM, Roh SA, Cho DH, Yu CS and Kim JC: Poorly differentiated colorectal cancers: Correlation of microsatellite instability with clinicopathologic features and survival. Am J Clin Pathol 140: 341-347, 2013. PMID: 23955452, DOI: 10.1309/AJCP8P2DYNKGRBVI 
25 Hutchins G, Southward K, Handley K, Magill L, Beaumont C, Stahlschmidt J, Richman S, Chambers P, Seymour M, Kerr D, Gray R and Quirke P: Value of mismatch repair, KRAS, and BRAF mutations in predicting recurrence and benefits from chemotherapy in colorectal cancer. J Clin Oncol 29: 1261-1270, 2011. PMID: 21383284, DOI: 10.1200/JCO.2010.30.1366

26 Vogelaar FJ, Erning FNV, Reimers MS, Linden HV, Pruijt H, Brule AJCVD and Bosscha $\mathrm{K}$ : The prognostic value of microsatellite Instability, KRAS, BRAF and PIK3CA mutations in stage II colon cancer patients. Mol Med 21: 1038-1046, 2016. PMID: 26716438, DOI: 10.2119/molmed.2015.00220

27 Claij $\mathrm{N}$ and te Riele $\mathrm{H}$ : Microsatellite instability in human cancer: A prognostic marker for chemotherapy? Exp Cell Res 246: 1-10, 1999. PMID: 9882509, DOI: 10.1006/excr.1998.4299

28 Fink D, Aebi S and Howell SB: The role of DNA mismatch repair in drug resistance. Clin Cancer Res 4: 1-6, 1998. PMID: 9516945

29 Branch P, Aquilina G, Bignami M and Karran P: Defective mismatch binding and a mutator phenotype in cells tolerant to DNA damage. Nature 362: 652-654, 1993. PMID: 8464518, DOI: $10.1038 / 362652 \mathrm{a} 0$

30 Kim JE, Hong YS, Kim HJ, Kim KP, Lee JL, Park SJ, Lim SB, Park IJ, Kim CW, Yoon YS, Yu CS, Kim JC, Hoon KJ and Kim TW: Defective mismatch repair status was not associated with DFS and OS in stage II colon cancer treated with adjuvant chemotherapy. Ann Surg Oncol 22: 630-637, 2015. PMID: 26271397, DOI: $10.1245 / \mathrm{s} 10434-015-4807-6$

31 Kuebler JP, Wieand HS, O'Connell MJ, Smith RE, Colangelo LH, Yothers G, Petrelli NJ, Findlay MP, Seay TE, Atkins JN, Zapas JL, Goodwin JW, Fehrenbacher L, Ramanathan RK, Conley BA, Flynn PJ, Soori G, Colman LK, Levine EA, Lanier KS and Wolmark N: Oxaliplatin combined with weekly bolus fluorouracil and leucovorin as surgical adjuvant chemotherapy for stage II and III colon cancer: Results from NSABP C-07. J Clin Oncol 25: 2198-2204, 2007. PMID: 17470851, DOI: $10.1200 / J C O .2006 .08 .2974$
32 Schmoll HJ, Cartwright T, Tabernero J, Nowacki MP, Figer A, Maroun J, Price T, Lim R, Van Cutsem E, Park YS, McKendrick J, Topham C, Soler-Gonzalez G, de Braud F, Hill M, Sirzén F and Haller DG: Phase III trial of capecitabine plus oxaliplatin as adjuvant therapy for stage III colon cancer: A planned safety analysis in 1,864 patients. J Clin Oncol 25: 102-109, 2007. PMID: 17194911, DOI: 10.1200/JCO.2006.08.1075

33 Yothers G, O'Connell MJ, Allegra CJ, Kuebler JP, Colangelo LH, Petrelli NJ and Wolmark N: Oxaliplatin as adjuvant therapy for colon cancer: Updated results of NSABP C-07 trial, including survival and subset analyses. J Clin Oncol 29: 37683774, 2011. PMID: 21859995, DOI: 10.1200/JCO.2011.36.4539

34 Casadaban L, Rauscher G, Aklilu M, Villenes D, Freels S and Maker AV: Adjuvant chemotherapy is associated with improved survival in patients with stage II colon cancer. Cancer 122: 32773287, 2016. PMID: 27417445, DOI: 10.1002/cncr.30181

$35 \mathrm{NIH}$ consensus conference. Adjuvant therapy for patients with colon and rectal cancer. National Institutes of Health. Conn Med 54: 573-581, 1990. PMID: 2265546

36 Quah HM, Chou JF, Gonen M, Shia J, Schrag D, Landmann RG, Guillem JG, Paty PB, Temple LK, Wong WD and Weiser MR: Identification of patients with high-risk stage II colon cancer for adjuvant therapy. Dis Colon Rectum 51: 503-507, 2008. PMID: 18322753, DOI: 10.1007/s10350-008-9246-Z

37 Li Y, Feng Y, Dai W, Li Q, Cai S and Peng J: Prognostic effect of tumor sidedness in colorectal cancer: A SEER-Based analysis. Clin Colorectal Cancer 2018. PMID: 30448100, DOI: 10.1016/j.clcc.2018.10.005 (Epub ahead of print)

Received January 10, 2019

Revised January 27, 2019

Accepted January 29, 2019 